\title{
An Integrated Modelling Approach Inmountainous Watershed of Heihe River Basin, Northwest China
}

\author{
Youjia Liang1,2*, Lijun Liu ${ }^{3}$, Zhongmin $\mathrm{Xu}^{1}$ \\ ${ }^{1}$ Cold and Arid Regions Environmental and Engineering Research Institute, Chinese Academy of Sciences, \\ Lanzhou, China \\ ${ }^{2}$ University of Chinese Academy of Sciences, Beijing, China \\ ${ }^{3}$ Gansu Meteorological Bureau, Lanzhou, China \\ Email: ${ }^{*}$ liangyj05@163.com
}

Received 19 November 2013; revised 23 January 2014; accepted 9 February 2014

Copyright $@ 2014$ by authors and Scientific Research Publishing Inc.

This work is licensed under the Creative Commons Attribution International License (CC BY).

http://creativecommons.org/licenses/by/4.0/

(c) () Open Access

\begin{abstract}
An integrated modelling approach is developed to simulate ecological economics processes of mountainous watershed of Heihe river basin, northwest China. The objectives are 1) a hydrologic unit model HLM_HMU was developed; 2) the impacts of LUCC on the hydrological processes based on different scenarios were simulated respectively; and 3) the Payment for Ecosystem Services (PES) curve of prohibition grazing is given. The hydrological results show that the observed and simulated data have a good fit, in which the Nash-Sutcliffe efficiency, balance error, and explained variance are $0.69,-0.13$, and 0.62 , respectively; the model can simulate the majority of peaks well; the source code of Spatial Modelling Environment (SME) needs to be deeply understood to improve the algorithms of interpolation and conflux; the PES result shows that prohibition grazing will occur completely when the price of PES reached to $\mathbf{1 7 . 4 2}$ yuan, and the increased amount of ecosystem services is $2.13 \times 10^{8} \mathrm{~m}^{3}$.The main purpose of this paper is to build a better understanding of developing a meaningful integrated model in the study area to solve its ecological and economic problems.
\end{abstract}

\section{Keywords}

Integrated Modelling; SME; Scenario Analysis; PES

\footnotetext{
${ }^{*}$ Corresponding author.
} 


\section{Introduction}

Integrated modelling and application has heightened as the extent and severity of environmental problems in the 21st century worsens [1]. The scale of integrated modelling is not restricted to the global level as in climate change models, but includes local and regional models of environmental problems. The earlier forms of systems modelling are being replaced with new integrated models that facilitate scenario generation and decision support functions. Unfortunately, the integrated research is still very weak in Heihe River Basin of Northwest China, which has led to many ecological and economic problems due to the water shortage [2].

The integration model of ecological and economic is much more complicated than single-process model. Establishing simulation model based on each single process, and then analyzing from a synthesis perspective is an efficient approach [3]-[5]. In the 2000s, scientists developed several high-quality ecological-economic models and a correlative of modelling environment [6]-[9]. These models consist of interrelated sub-models between ecological and economic system, and embeds local simulation models into a spatial context. At the same time, the development of integrated modelling environment is integrating scientific and socioeconomic knowledge, which also is increasing the efficiency of decision making, such as management of water resources. For example, SME has been developed as a powerful tool to facilitate the model building process (http://www.uvm.edu/giee/SME3/). In general, the ecological-economic models including natural and human factors. As an interaction interface for human activity and the environment, Land Use/Cover Change (LUCC) is an effective way to deepen understanding of the coupled human-terrestrial environment system [10].

The aims of this paper are: 1) based on SME, a hydrology unit model (HLM_HMU) with system dynamics software STELLA7.0 was established; 2) the impacts of LUCC on the hydrological processes were simulated respectively based on scenarios of base period and prohibition grazing. The spatial distribution of soil moisture based on different scenarios was produced at the daily scale; and 3) integrated with method of Payments for Ecosystem Services (PES), we got the PES price curve by using Minimum Data (MD) model, based on soil moisture and Opportunity Cost (OC) of prohibition grazing. Thus, we constructed an integrated modelling framework which can reflect the coupling process of natural and human in the study area.

\section{Data and Methods}

\subsection{Study Area}

The Heihe River basin is the second largest inland river basin in northwestern China, having a drainage area of $1.3 \times 105 \mathrm{~km}^{2}$. The basin includes the montane zone of the Qilian Mountains, the Hexi Corridor plains in the middle, and the lower montane zone and Alashan Plateau in the north. The basin is characterized by a scarcity of water resources, and severe deterioration of the water environment has already adversely affected the possibility of sustainable regional development. Our study area was located in the upper reaches of the Heihe River basin (see Figure 1). The altitude ranges from 1674 to $5076 \mathrm{~m}$, and annual mean temperature varies from $-5^{\circ} \mathrm{C}$ to $4^{\circ} \mathrm{C}$. The annual total precipitation averages more than $200 \mathrm{~mm}$, and increases to $600-700 \mathrm{~mm}$ at higher altitudes. The land use types mainly including grassland, woodland, water, human settlement and unused land. The surface condition is extremely complex, and because of the scarcity of hydrological and meteorological observation stations, the field experimental data is limited.

\subsection{Data}

Meteorological data (1996-2009), soil map (2009) and LUCC (1996-2009) derived from the Environment and ecological science data center of western China (http://westdc.westgis.ac.cn). Geo-rectification and clip of raster data were conducted using software ERDAS9.0. The main land use type is grassland. We also got the household OCdata of prohibition grazing from March 28 to April 12 in 2011, and the survey had covered all the area of the upper reaches of the Heihe River basin. 150 questionnaires were distributed and got 137 valid questionnaires, and the percent of efficiency is 91.33\%. The Defense Meteorological Satellite Program (DMSP) F16 night light radiation data in 2009 (http://www.ngdc.noaa.gov/dmsp/) was used to generate a spatial map of OC.

Besides, auxiliary data were collected for the integrated modelling from the Digital River Basin website (http://heihe.westgis.ac.cn/), which including: Digital Elevation Model (DEM, 100 m), maps of slope and aspect, maps of groundwater depth and groundwater quality, a hydro-geological map. All the raster data were uniformly 


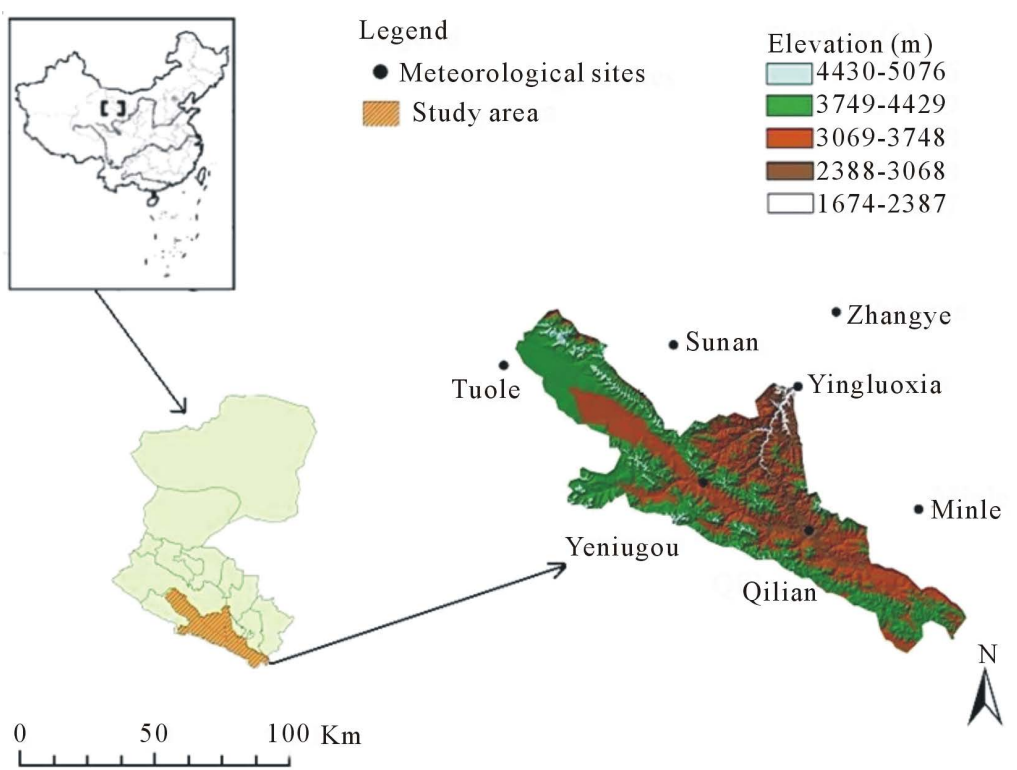

Figure 1. Location of the study area.

projected into Transverse Mercator projection, and reproduced with $500 \mathrm{~m}$ resolution.

\subsection{HLM_HMU Model}

The model including following state variables: surface water, snow/ice, liquid water of unsaturated zone, solid water of unsaturated zone and water of saturated zone. The corresponding hydrological processes are precipitation, interception, infiltration, evapotranspiration, percolation and recharge. The horizontal flow can be driven through SME algorithm (http://giee.uvm.edu/LHEM). The C++ code which have modified and extended to suit requirement of the model. So we focus on the structure description of vertical flow.

\subsubsection{Precipitation}

First, the observation results of meteorological station have wind power loss, evaporation loss and wet loss which need to correct [11]. In the model, solid precipitation correction coefficient Co_Snow is 1.3, and liquid precipitation correction coefficient ${ }_{0}$ _Rain is 1.1. Then, another important sub-process is interception, which occurred before separation of solid and liquid precipitation. The value of interception is the maximum amount between precipitation, non-vegetation interception and vegetation interception, and not more than the minimum amount of precipitation. Last, we assumed that precipitation is liquid when the average daily temperature is greater than the liquefaction critical temperature Co_Snow Rain, and it is solid when the temperature is less than the solidify critical temperature $\mathrm{Co}_{-}$Rain Snow, and the two values are set to $4{ }^{\circ} \mathrm{C}$ and $0^{\circ} \mathrm{C}$ separately.

\subsubsection{Freeze and Melt of Surface Zone}

If the average daily temperature is less than the temperature value of seasonal snow melt, accumulating of solid precipitation and freezing of liquid precipitation. The freeze coefficient $C_{-} S W \_$freeze depends on the surface habitat types. If the average daily temperature is greater than or equal to the temperature value of snow melt, the degree-day factor method [12] is used and gained a minimum value between the calculative amount of melt and actual melt. The value of melting factor of snow and glaciers is $5 \mathrm{~mm} \cdot \mathrm{d}^{-1} \cdot{ }^{\circ} \mathrm{C}^{-1}$.

\subsubsection{Infiltration}

Infiltration is defined by the potential infiltration and unsaturated storage that is currently available for unsaturated capacity.

$$
P_{-} I=\frac{C_{-} I \times\left(C_{-} P-C_{-} U_{-} m_{-} p-C_{-} U_{-} s_{-} p\right)}{C_{-} I_{-} S}
$$


where $P \_I$ is potential infiltration $(\mathrm{mm}), C_{-} I$ is modifier of infiltration, $C_{-} P$ is soil porosity, $C_{-} I \_S$ is slope modifier, $C \_U \_M \_P$ is moisture proportion of unsaturated storage, $C \_U \_S \_P$ is solid water proportion of unsaturated storage. The unsaturated capacity is the total volume of soil pores that is not yet taken by water:

$$
U n_{-} \text {cap }=U W_{-} \text {depth } \times\left(C_{-} P-C_{-} U_{-} m_{-} p-C_{-} U_{-} s_{-} p\right)
$$

where $U W \_$depth is depth of unsaturated storage $(\mathrm{mm})$. $S \_W$ is rest volume of surface water, and other variables are as described earlier. The amount of infiltration $\left(U W \_P\right)$ from surface to unsaturated layer is:

$$
U W_{-} P=\min \left(U_{-} c a p, \min \left(S_{-} W, P_{-} I\right)\right)
$$

\subsubsection{Evapotranspiration}

Potential transpiration was got from Christiansen model [13], and potential evaporation was calculated by using the modified FAO Penman-Monteith model [14]. Actual evapotranspiration includes soil evaporation and vegetation transpiration. It assumed that evapotranspiration occur when the proportion of unsaturated zone was higher than withering point (assumed to 10\% of field capacity), otherwise it does not occur.

$$
\begin{gathered}
\text { Evap_s }=C_{-} \text {evap } \_s \times E T p m \times U W_{-} m p_{-} r \\
U W_{-} m p_{-} r=\frac{C_{-} U_{-} m_{-} p}{C_{-} P}
\end{gathered}
$$

where Evap_s is actual soil evaporation $\left(\mathrm{m} \cdot \mathrm{d}^{-1}\right)$, C_evap_s is an evaporation modifier which depend on soil types, $E T p m$ is potential evaporation $\left(\mathrm{m} \cdot \mathrm{d}^{-1}\right), U W \_m p \_r$ is relative proportion of soil moisture.

$$
E v a p_{-} h=C_{-} e v a p_{-} h \times E T c \times U W_{-} m p \_r \times M a c L A I
$$

where Evap $h$ is actual vegetation transpiration $\left(\mathrm{m}^{\cdot} \mathrm{d}^{-1}\right)$, C_evap_h is regulation factor, ETc is potential transpiration $\left(\mathrm{m} \cdot \mathrm{d}^{-1}\right)$, MacLAI is leaf area index. The total evapotranspiration of each grid is expressed as follows:

$$
U W_{-} \text {evap }=C_{-} \mathrm{Cov}_{-} p \times \mathrm{Evap}_{-} h+\left(1-C_{-} \mathrm{Cov}_{-} p\right) \times \mathrm{Evap}_{-} \mathrm{s}
$$

where $U W \_$evap is the total evapotranspiration ( $\left.\mathrm{mm} / \mathrm{d}\right), C \_c o v \_p$ is the vegetation coverage proportion of each grid, and other variables are as described earlier.

\subsubsection{Freeze and Melt of Unsatured Zone}

The freezing water of unsaturated zone can be expressed as follows:

$$
U W_{-} f=\left\{\begin{array}{lc}
\text { UNSAT_WATER } & \text { DW_temp }<-8 \\
\text { UNSAT_WATER } \times \frac{0-D W_{-} \text {temp }}{0-(-8)} & -8 \leq D W_{-} \text {temp } \leq 0 \\
0 & D W_{-} \text {temp }>0
\end{array}\right.
$$

where $U W \_f$ is the amount of frozen unsaturated water $\left(\mathrm{m} \cdot \mathrm{d}^{-1}\right), U n \_W$ is initial amount of unsatured zone water (m), DW_temp is the ground temperature $\left({ }^{\circ} \mathrm{C}\right)$. The melting water of unsaturated zone $U W \_m\left(\mathrm{~m} \cdot \mathrm{d}^{-1}\right)$ can be expressed as follows:

$$
U W_{-} m= \begin{cases}0 & D W_{-} \text {temp }<-8 \\ U N S A T \_W A T E R \times \frac{D W_{-} \text {temp }-(-8)}{0-(-8)} & -8 \leq D W_{-} \text {temp } \leq 0 \\ \text { UNSAT_WATER } & D W_{-} \text {temp }>0\end{cases}
$$

\subsubsection{Unsatured to Satured Zone}

When unsaturated water exceeds field capacity, part of the unsaturated water leaks into the saturated zone due to gravity. When the soil moisture ratio is below field capacity, all the unsaturated water is retained by capillarity and adhesion action and there is no leakage. Therefore, the leakage of water can be given by: 


$$
\begin{gathered}
U W_{-} e=U W_{-} m_{-} p r{ }_{-} C_{-} f_{-} \text {cap } \\
U W_{-} p e r c_{-} r=\frac{2 * C_{-} v e r t_{-} h_{-} c \times C_{-} P \times\left(U W_{-} e\right)^{0.4}}{\left(C_{-} P-C_{-} f_{-} c a p\right)^{0.4}+\left(U W_{-} e\right)^{0.4}}
\end{gathered}
$$

where $U W \_e$ is the amount of percolation, $C \_f \_c a p$ is field capacity, $U W \_p e r c \_r$ is the rate of percolation $\left(\mathrm{m} \cdot \mathrm{d}^{-1}\right), C \_$vert_h_c is vertical hydraulic conductivity.

\subsection{Opportunity Cost}

Some regions of sparsely populated cannot take the household survey. Therefore, we got the spatial distribution of OC by using spatialization technology which based on DMSP F16 data, DEM, the OC survey data and GPS points. Extracting the values of digital number and elevation which corresponding to the survey points data by using ArcGIS9.0. Thus, the Equation (12) of OC for each grid is gotten by using non-linear curve fitting method of matlab7, and the function is the Gauss-Newton and Universal global optimization.

$$
\begin{aligned}
O C= & \left(133279.43+14156.77 \times S L-931.06 \times S L^{2}-226.70 \times D+0.11 \times D^{2}\right. \\
& \left.-1.46 \times D^{3}\right) /\left(1-348.37 \times S L+74.51 \times S L^{2}-4.13 \times S L^{3}+0.7 \times D\right)
\end{aligned}
$$

where $S L$ is the digital number, $D$ is elevation. The RMSE of Equation (12) is 2.51, correlation coefficient is 0.84 , and determination coefficient is 0.71 . Finally, we got the OC distribution of prohibition grazing (Unit: yuan, at present, \$1U.S. = 6.09yuan, see Figure 2).

\subsection{Model}

MD model exploits the structure of the PES problem to obtain an approximation of the ecosystem services (ES) supply curve using relatively simple secondary data, and it assumes farmers are rational economic men who make land use and management decisions to maximize their perceived economic returns [15]. These decisions may impact on ecosystem function and the supply of ES by affecting biological and physical systems through a number of mechanisms.

We assume that the prohibition grazing scenario $S$ is a water-conserving practice and produces more ES than scenario $B$ (grazing). We assume that a quantity ES of $e$ units per time period is produced when scenario $S$ is adopted, and different types of grassland will become high coverage grassland, and a land use map of scenario $S$ can be gotten in the study area. The density function can be defined as

$$
\varphi(w / e)=w / e,
$$

where $w$ is the difference of expected net returns between two scenarios, and parameter $e$ is interpreted as the rate of ES obtained from changing land use. The proportion of scenario $B$ without payments $r(p)$ and initial supply of ES without other financial incentives $S(p)$ are given by:

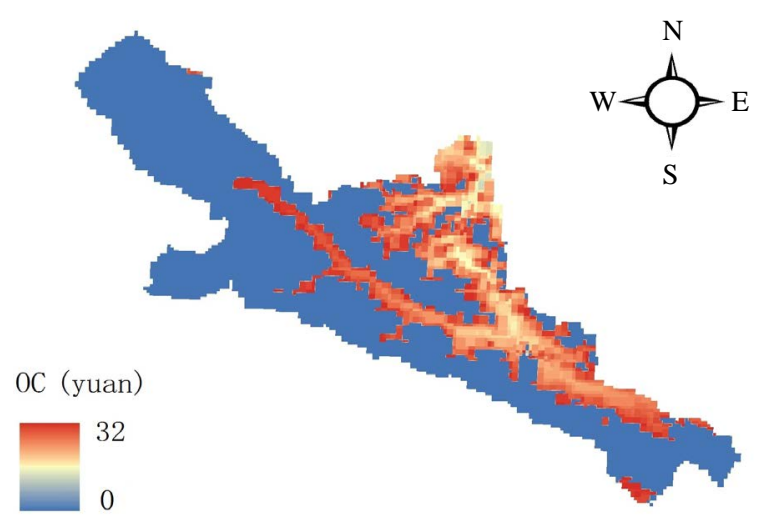

Figure 2. The map of OC for prohibition grazing in the study area at 2011. 


$$
\begin{gathered}
r(p)=\int_{-\infty}^{0} \varphi(w / e) \cdot \mathrm{d}(w / e) \\
S(p)=r(p) \cdot H \cdot e
\end{gathered}
$$

where $H$ is total area of grassland $\left(\mathrm{km}^{2}\right)$. We assume that a payment price $p_{e}$ is offered to farmers to stimulate them to change their land use from practice $B$ to $S$. The total ES amount $S\left(p, p_{e}\right)$ are given by:

$$
S\left(p, p_{e}\right)=S(p)+r\left(p, p_{e}\right) \times H \times e
$$

\section{Results}

\subsection{HLM_HMU}

The spatial model was calibrated and validated by comparing observed and simulated runoff of Yingluoxia hydrological station for 1996-2000 and 2004. The main calibration parameters are seen in Table 1.

Based on HLM_HMU and SME, we got the simulated values of daily surface runoff in Yingluoxia hydrological station in 1996-2011. The simulation results showed that the observed and simulated runoff has an overall good fit (see Figure 3), especially in autumn and winter, while the spring-simulated values are generally higher than observed. Most of the summer peak can be fitted. But a small number of peaks are not simulated, and this may be a result of the rare rainfall in autumn and winter, when runoff is also decreased. Adjusting the snow-melt factor to address the higher simulated values in spring, but it will also affect the follow-up process and reduce simulation accuracy. Rainfall is the main source of runoff in summer. However, a more complex physical mechanism of snow/ice melting and freezing process should be included in the model in the future, rather than controlling their changes with critical temperature.

Three statistical indicators [16]-[18], the Nash-Sutcliffe efficiency (NSE), Balance error (B), and Explained Variance (EV) were used to evaluate the result. The calibration result of NSE is $0.69, B$ is -0.13 , and $\mathrm{EV}$ is 0.62 . It showed that the model structure has certain stability.

We selected soil moisture of unsaturated layer as an indicator to reflect ES supply. HLM-HMU model is configured in SME, and produced as spatial output variables. Then, we got the value of average soil mois-

\begin{tabular}{|c|c|c|}
\hline Parameter & Meaning & Value \\
\hline MacLAI & Vegetation LAI & Vegetation map \\
\hline C_SW_melt & Melt factor & Land use map \\
\hline$C \_c o v \_p$ & Vegetation coverage & Vegetation map \\
\hline$C \_P$ & Soil porisity & Soil map \\
\hline$C \_f \_c a p$ & Field capacity & Soil map \\
\hline Co_Rain & Adjustment factor of rainfall & 1.1 \\
\hline CO_Snow & Adjustment factor of snow & 1.3 \\
\hline co_SnowRain & Critical temperature & 2 \\
\hline$U W \_m p \_r$ & Initial moisture proportion of unsaturated layer & 0.3 \\
\hline C_intercep & Interception coefficient of precipitation & 0.05 \\
\hline C_evap & Adjustment factor of potential evaporation & 0.0081 \\
\hline C_evap_h & Adjustment factor of vegetation transpiration & 0.13 \\
\hline C_evap_s & Adjustment factor of soil evaporation & 0.45 \\
\hline C_base_flow & Adjustment factor of base flow & 0.002 \\
\hline C_I & permeability coefficient & 0.28 \\
\hline C_SW_freeze & Freeze coefficient of surface water & 0.0005 \\
\hline
\end{tabular}
ture which based on every first, middle and last month day's results from May to September. Thus, we got

Table 1. Set of main calibration parameters in HLM_HMU. 


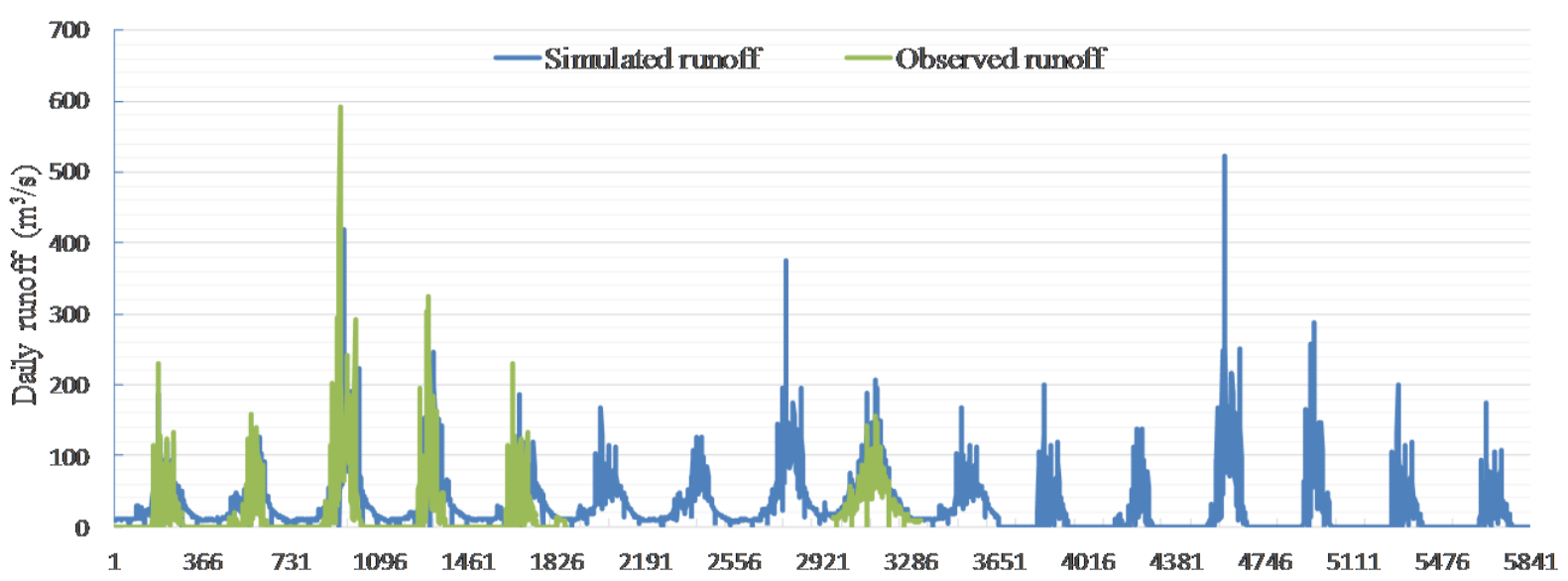

Figure 3. Comparison of simulated and measured runoff in Yingluoxia hydrological station from 1996 to 2011.

different results based on scenarios of B and S, and we found the soil moisture of southeast region generally increased in scenario $\mathrm{S}$.

Contrasting results of scenario $\mathrm{S}$ and $\mathrm{B}$, we got spatial distribution of increased soil moisture. Combining with the OC distribution in the study area at 2011, we got the distribution of OC corresponding with per increased amount of ES. The increased region is mostly located in Sunan County where there are more disturbances by human activities, and no-human's regions basically did not change significantly.

\subsection{Analysis of Scenario B and S}

The total ES value of scenario B is given by using Equations (13), (14), and the total value is $8.97 \times 10^{8} \mathrm{~m}^{3}$ (see Figure 4), and distribution of various grassland types without PES in the study area are: high coverage grassland $2243 \mathrm{~km}^{2}$, medium coverage grassland $2558 \mathrm{~km}^{2}$, low coverage grassland $641 \mathrm{~km}^{2}$, which accounted for $26.89 \%$, $30.68 \%$ and $7.69 \%$ of the total watershed area respectively.

When scenario S happens, the relationship between proportion of increased high coverage grassland and payment price is shown in Figure 5. A half proportion of high coverage grassland will be added in the scenario $S$ when the payment price is 1.22 yuan. The scenario $S$ will happen totally when the payment price is 17.42 yuan, and the grassland of low-middle coverage will disappear, area of high coverage grassland will become to $5442 \mathrm{~km}^{2}$, accounting for $65.26 \%$ of the watershed area. The total value of ES is $3.03 \times 10^{9} \mathrm{~m}^{3}$ (see Figure 4) and the total payment price is $156.25 \times 10^{8}$ yuan.

\section{Discussion}

The objective of this study is to develop a coupled ecological-economic model for evaluating the LUCC effects of different management scenarios on supply of ecosystem service in mountainous watershed of Heihe River basin, Northwest China. Because of the high complexity and large uncertainties in parameters and processes, any numerical estimates are intended to be used with caution; nevertheless, the model can offer useful information to those currently addressing degradation of ecological systems in the study area.

The high data requirement and computational complexity slowed model development; the integrated modelling approach tries to find a balance between simple and general by minimizing complexity while providing enough process-oriented, spatial-temporal explicit information for management purposes. Spatial data is becoming available for analyses and our modelling approach is able to take advantage of spatial dynamic data in its relatively raw form without being forced to use complex spatial or temporal aggregation schemes.

The SME allowed integration of several independently Stella models. The Stella model formulation is translated and loaded into the SME, which puts the local model into the spatial context, offering the input/output capabilities needed to handle spatial data. This helps visualize the process and leads to faster development times. In the current formulation of the SME, Stella runs on Windows operating systems, while the SME runs under Linux. In the future, the spatial interpolation method needs to be improved by decoupling the SME source code to make it more applicable to complex terrain conditions in the study area. 


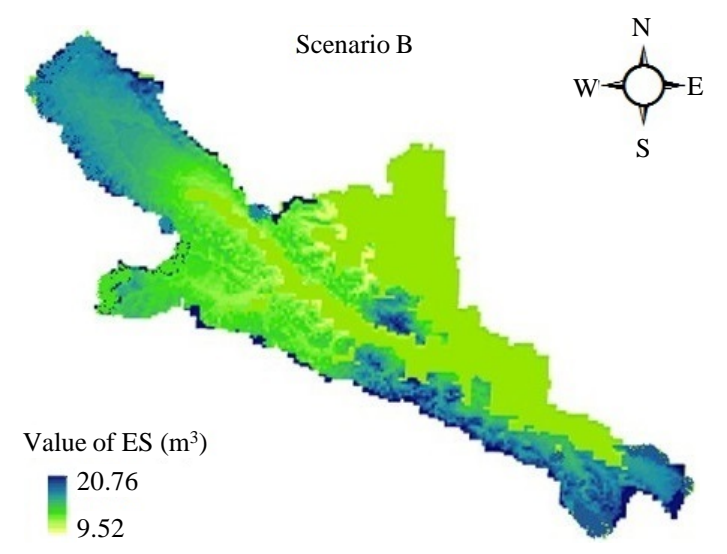

(a)

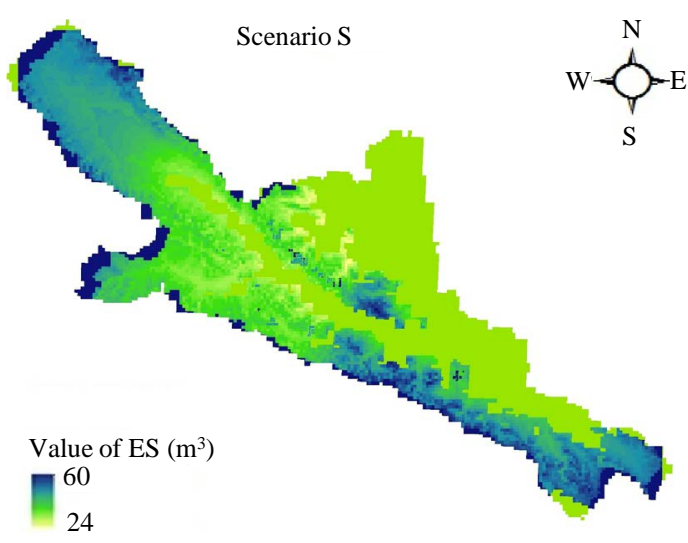

(b)

Figure 4. The distribution of ES value based on scenario B and S in 2011.

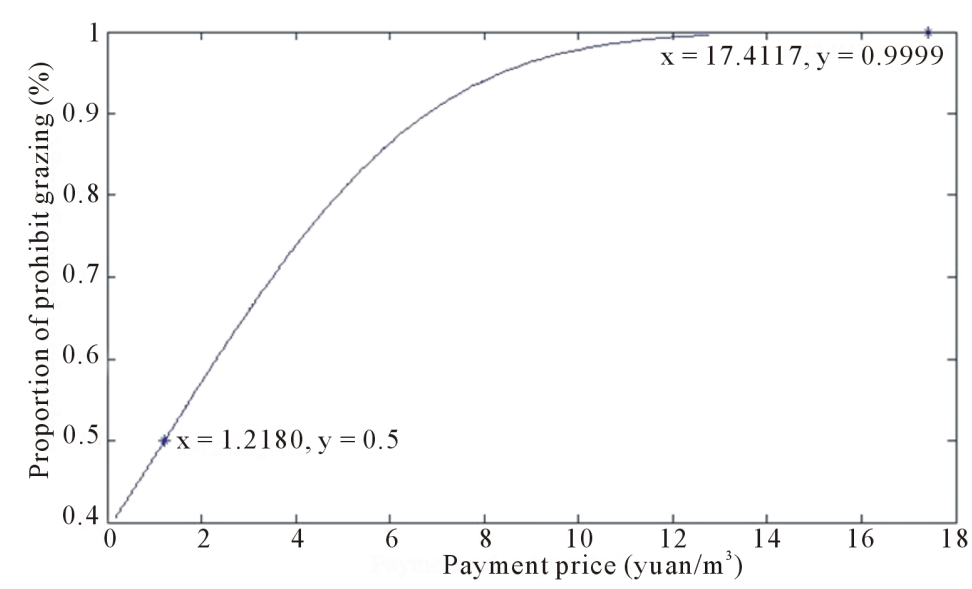

Figure 5. The relationship between proportion of increased grassland and payment price in 2011.

\section{Conclusion}

In summary, the development of the approach is just a basis for establishing a more complete model. To achieve a better integrated model, plant growth, nutrient dynamics and more complex human activities should be added to the current integrated modelling framework to grasp the overall dynamics of ecological-economic system. More importantly, the study area needs to expand to the middle and lower reach to improve the analysis precision for influence of human factors on water resource systems and landscape pattern changes.

\section{Acknowledgements}

The authors wish to acknowledge the support of the National Basic Research Program of China (Contract No. 91125019).

\section{References}

[1] Costanza, R. and Ruth, M. (1998) Using Dynamic Modelling to Scope Environmental Problems and Build Consensus. Environment Management, 22, 183-195.http://dx.doi.org/10.1007/s002679900095

[2] Cheng, G.D., Xiao H.L. and Li, C.Z. (2008) Water Saving Eco-Agriculture and Integrated Water Resources Management in the Heihe River Basin, Northwest China. Advances in Earth Science, 23, 661-665.

[3] Schellnhuber, H.J. (1999) Earth System Analysis and the Second Copernican Revolution. Nature, 402, 19-23. 
http://dx.doi.org/10.1038/35011515

[4] Monfreda, C., Wackernagel, M. and Deumling, D. (2004) Establishing National Natural Capital Accounts Based on Detailed Ecological Footprint and Biological Capacity Assessments. Land Use Policy, 21, 231-246. http://dx.doi.org/10.1016/j.landusepol.2003.10.009

[5] Suarez, R.M., Lookingbill, T. and Wainger, L. (2012) Modelling Exurban Development near Washington, DC, USA: Comparison of a Pattern-Based Model and a Spatially Explicit Econometric Model. Landscape Ecology, 27, 10451061. http://dx.doi.org/10.1007/s10980-012-9760-1

[6] Woodwell, J. (1998) A Simulation Model to Illustrate Feedbacks among Resource Consumption Production and Factors of Production in Ecological Economic Systems. Ecological Modelling, 112, 227-248. http://dx.doi.org/10.1016/S0304-3800(98)00080-5

[7] Costanza, R., Voinov, A., Boumans, R., Maxwell, T., Villa, F., Voinov, H. and Wainger, L. (2002) Integrated Ecological Economic Modelling of the Patuxent River Watershed, Maryland. Ecological Monographs, 72, $203-231$. http://dx.doi.org/10.1890/0012-9615(2002)072[0203:IEEMOT]2.0.CO;2

[8] Voinov, A., Fitz, C., Boumans, R. and Costanza, R. (2004) Modular Ecosystem Modelling. Environmental Modelling \& Software, 19, 285-304. http://dx.doi.org/10.1016/S1364-8152(03)00154-3

[9] Voinov, A., Costanza, R., Fitz, C. and Maxwell, T. (2007) Patuxent Landscape Model: 1. Hydrological Model Development. Water Resource, 34, 163-170. http://dx.doi.org/10.1134/S0097807807020066

[10] Wang, J., Fu, B.J., Yang, Q. and Chen, L.D. (2001) Soil Nutrients in Relation to Land Use and Landscape Position in the Semi-Arid Small Catchment on the Loess Plateau in China. Journal of Arid Environments, 48, 537-550. http://dx.doi.org/10.1006/jare.2000.0763

[11] Kang, E.S., Cheng G.D., Lan, Y.C. and Jin, H. (1999) A Model for Simulating the Response of Runoff from the Mountainous Watersheds of Inland River Basins in the Arid Area of Northwest China to Climatic Changes. Science in China Series D: Earth Sciences, 42, 52-63. http://dx.doi.org/10.1007/BF02878853

[12] Chen, R.S., Lv, S.H. and Kang, E.S. (2006) A Distributed Water-Heat Coupled (DWHC) Model for Mountainous Watershed of an Inland River Basin (I): Model Structure and Equations. Advances in Earth Science, 21, 806-818.

[13] Saxton, K.E. and McGuinness, J.L. (1982) Evapotranspiration. Hydrologic modeling of small watersheds, 5, $229-273$.

[14] Liang, Y.J. and Xu, Z.M. (2011) Research on Estimation of Penman-Monteith Modified Model in the Middle Reaches of Heihe River Based on System Dynamics. Pratacultural Science, 28, 18-26.

[15] Kelly, J., Wendland, M.H. and Rosimeiry, P. (2010) Targeting and Implementing Payments for Ecosystem Services: Opportunities for Bundling Biodiversity Conservation with Carbon and Water Services in Madagascar. Ecological Economics, 69, 2093-2107. http://dx.doi.org/10.1080/02626669609491557

[16] Nash, J.E. and Sutcliffe, J.V. (1970) River Flow Forecasting through Conceptual Models, 1: A Discussion of Principles. Journal of Hydrology, 10, 282-290. http://dx.doi.org/10.1016/0022-1694(70)90255-6

[17] Loumagne, C., Chkir, N. and Normand, M. (1996) Introduction of the Soil/Vegetation/Atmosphere Continuum in a Conceptual Rainfall/Runoff Model. Hydrological Sciences Journal, 41, 889-902. http://dx.doi.org/10.1080/02626669609491557

[18] Franchini, M. and Pacciani, M. (1991) Comparative Analysis of Several Conceptual Rainfall-Runoff Models. Journal of Hydrology, 122, 161-219. http://dx.doi.org/10.1016/0022-1694(91)90178-K 